\title{
Editorial
}

\section{Nothing Forever: Special Issue on Mindfulness and Improvisation}

\section{Anton Krueger}

Rhodes University, Department of Drama, Makhanda, South Africa

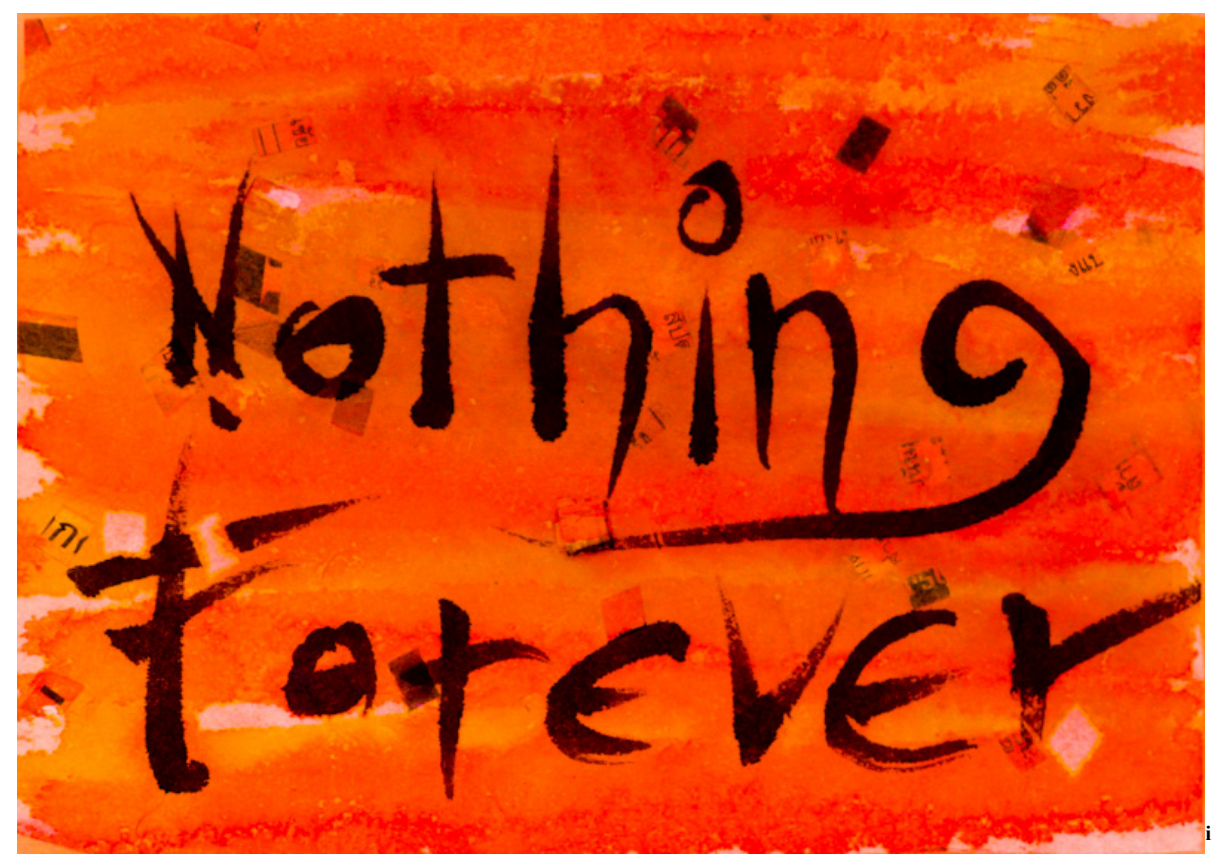

\section{Overview of Special Issue}

Thank you to everybody who made contributions to this bumper 2021 Special Issue on Improvisation. Many thanks to our peer reviewers and especially to co-editors Deborah and Daniel for their help with the selection and editing process which has now culminated in a baker's dozen texts. With contributions from Australia, South Africa, and New Zealand, as well as from France, the USA and the UK, the issue includes five interviews, four articles, two book reviews, a reflection and a score. 
Initially, I was hoping to put together a book on the topic of Mindfulness and Improvisation, and in 2020, I held around thirty interviews with practitioners from all over the world. I was then invited to edit this journal issue and some of what was to be the abstract for the book went into the call for papers. (l've included a couple of pages from this at the end of this editorial, to indicate some of the ways in which the fields of Mindfulness and Improvisation intersect.) Five of these interviews made it into the journal issue. We decided to call them 'conversations' since I invariably ended up talking too much and didn't always stick to the questions, (nor, for that matter, to the point). Here, then, are somewhat improvised conversations with Stephen Nachmanovitch, Patricia Ryan Madson, Lee Worley, Al Wunder and Andrew Morrish.

I first started editing the interviews l'd done with people who'd made submissions to the issue, or whose books had been reviewed, and the next thing you know it was the end of the year already. My apologies to those whose interviews we have unfortunately not been able to include. There were just too many, and not enough time! I so enjoyed all the fascinating discussions held and am hopeful that I will still be able to get around to editing and publishing more of them. And if my dream of an eventual book project materialises, the interviews will certainly provide core material towards that research.

In terms of the articles selected for publication; we had a large range of submissions to choose from, and peer reviewers and editors eventually settled on four, by: Lee Worley, Min Zhu, Ann Moradian and Jeremy Mayall. The articles presented here are on subjects which are not often dealt with in academic publishing, and they all include an element of practical performance praxis developed by individual authors.

Lee Worley's article draws on her training with Chögyam Trungpa and reflects on the use of a lesser-known Tibetan teaching on the 'four karmas' (pacifying, enriching, magnetizing, and destroying). She's created a unique methodology which incorporates these teachings into the actor training curriculum she developed for her acting students at Naropa.

Min Zhu's work on Tai Ji Quan (Tai Chi) engages with qi as a tool to facilitate spontaneity. Traditionally seen as 'an effective means of achieving the spiritual unity of the body,' Zhu shows how TJQ can also be utilized as a mindfulness-based practise which can be 'innovatively applied to contemporary performer training, especially in the form of improvisation.' Her philosophical reflection on working within this discipline includes practical examples from her workshops at the Western Australian Academy of Performing Arts. 
Ann Moradian's article explores how movement improvisation can be used as a transformational tool for dealing with complexity. Coming from her own work as Artistic Director of the Parisian company Perspectives in Motion, she draws on a range of influences from RD Laing to David Abrams. She describes movement improvisation as part of the process of breathing 'life and movement back into our selves, back into the animate and interdependent worlds we are a part of,' which she sees as being no less than 'a necessary and fundamental step in bringing ourselves back to life.'

Jeremy Mayall's article reflects on his own practise as improvisational musician with an outfit called Dr Mesmer's Private Army. Mayall's work has a special contemporary relevance, since it draws on work created for an online performance series taking place under lockdown. His work is 'designed to provide space for shared improvisation as a tool for mindfulness in uncertain times'. Using intuitive, slow improvisation, participants in these performances 'were forced to embrace the uncertainty of the environment and technology, and to recognise the spontaneity of improvisational experiences that are mediated through the experience of shifting time, and the disembodied nature of Zoom, to create music that has a sense of release and connection.' l'd encourage readers to also follow the many hyperlinks in Jeremy's essay to hear some of the wonderful music that Dr Mesmer's Private Army have produced.

Since many artists and practitioners of improvisation are not necessarily traditional academics, we also created a new category for this issue called 'Reflections, Reviews and Interviews,' which were not peer reviewed. For example, in her insightful essay 'Improv, a Venue for Values: Teaching Kindness', Patricia Ryan Madson reflects on her work at Stanford University in which she has used improvisation as a means of teaching 'the virtue of kindness.' Patricia is one of the pioneers in the practical application of improvisation in mindfulness and daily life, and her book Improv Wisdom (2005) has inspired tens of thousands. She was one of the first people I interviewed for this project and has remained a warm and encouraging presence.

John Britton's review of Stephen Nachmanovitch's new book, The Art of Is (2019), shows that it's destined to become a classic, alongside his seminal Free Play (1991), and Tamarisk Glogauer's review of The Motional Improvisation of Al Wunder, by H.R. Elliott describes how the book 'invites the reader to consider ...the ripples that continue to fan out from [Wunder's] dance lineage.' Both reviews provide excellent companion pieces to the 
interviews with Nachmanovitch and Wunder.

Finally, Sandra Paola López Ramírez offers 'Meeting the Body-Space: an 11-step score', which is 'a performance score ...to synchronize body, mind, and spirit.' In many ways the integration of bodymind and space is a theme that has come up in almost all the pieces in this issue, so this score provides an embodied touchstone for the other texts.

Thank you again to the many people who put in the time and effort to reflect on and frame their experiences as artists and thinkers. I'm sorry that we were not able to include everybody who submitted texts, or everybody who graciously gave of their time for the interviews. I do hope that the energy generated by these activities will encourage the fields of both improvisation and mindfulness to flourish.

Anton Krueger

January, 2022

Rhodes University, Makhanda, South Africa 


\section{Introductory Notes on the Relationship between Improvisation and Mindfulness}

\section{(from the initial call for papers)}

There are many implicit resonances between improvisation and mindfulness. For example, in Keith Johnstone's Impro (1979), improvisers are encouraged to practise 'accepting ... not blocking' (95); to develop 'spontaneity' (32); to cultivate 'stillness' (20) and to 'stop thinking ahead' (104) - all terms used in mindfulness training. Many teachers of improvisation emphasise the ontological aspects of their training, and John Abbot goes as far as referring to 'the ability to 'be there" as the 'main skill' an improviser needs to develop (2007:43). Similarly, the Mindfulness Association (UK) curriculum suggests 'approaching the mindfulness support from the mode of being, rather than the mode of doing' (2013:51). This Special issue has set out being curious about ways in which the tenets of improvisation in all its forms might be similar to mindfulness practices.

In her writings, Viola Spolin hints at a connection to mindfulness when she speaks of the 'timeless moment, when all are mutually engaged in experiencing and experience, the outcome of which is as yet unknown' (2001:x). She describes the present moment as 'a moment of full consciousness, awareness' (xiii) and goes as far as to talk of 'meditation in action,' (1999:x), and a form of play which 'quiets the mind and frees players' (Lv). Spolin also describes the moment of play as 'knowing what is happening' (7), which is similar to the 'clear sighted vision' (2021) Al Wunder encourages. Both descriptions relate to Rob Nairn's definition of mindfulness as 'knowing what is happening while it is happening, without preference' (2019:19).

In both mindfulness and improvisation one finds a demonstration of Jacques Lecoq's notion of disponsibilité, which relies on 'Availability - openness - readiness - acceptance: the precondition of creativity. It implies not resisting but flowing with the world and the self' (Frost and Yarrow, 2007:196). Both improvisation and mindfulness techniques encourage responsivity, rather than reactivity; and many of the top ten elements identified as the building blocks of Applied Improv in the Delphi Study (Tint and Froerer) relate to elements within mindfulness practises, including 'curious listening... complete acceptance... flexibility/spontaneity... focus on here and now.... personal awareness' (2014:2).

There are also ethical implications of working with vulnerability and openness in a compassionate and non-judgemental way. Improvisation works with the unknown, and it can 
be disconcerting to move the focus of awareness away from one's 'sense of self,' which is so often bolstered by division and separation from others. Many of the essays in this issue reflect on ways of integrating experiences.

Musical improvisation (extemporization) is associated with Jazz as form, but also with the work of Pauline Oliveros and her framing of what she called 'Deep Listening', a technique closely aligned to mindfulness practises using sound as support. In dance and movement, improvisation is today associated with contact improv, but its contemporary roots go all the way back to the beginnings of modern dance itself, to performers such as Isadora Duncan and Martha Graham, and also, of course, Judson Dance Theatre.

The implications of improvisation for creative processes are far reaching. For Frost and Yarrow '[i]mprovisation may be close to pure creativity,' and a key to 'the way in which we respond to and give shape to our world' (2007:2). Simon Rose takes this even further, seeing improvisation as 'a pervasive aspect of being human, in every sphere of life, enabling existence' (2017:1). Improvisation can also be seen in the way we build knowledge, taking steps into the unknown from the platform of the known. Theresa Hardman, for example, identifies an improvisatory approach in Deleuze and Guattari's description of 'lines of flight' and 'deterritorialization' which are comparable to the intuitive leap improvisation demands (2019:90-92).

There are thus wide-ranging implications for this study of mindfulness and improvisation and this Special Issue hopes to capture some of these resonances.

\section{Works Cited}

Abbott, John. 2007. The Improvisation Book. London: Nick Hern Books.

Frost, Anthony \& Yarrow, Ralph. 2007. Improvisation in Drama, Second Edition, Hampshire: Palgrave Macmillan. [First Edition: 1990].

Hardman, Theresa Jane. 2019. Understanding Creative Intuition - Perspectives from Eastern and Western Philosophy. PhD thesis, Doctor of Philosophy, University of the Free State, South Africa.

Johnstone, Keith. 1979. Impro. London: Faber and Faber.

Mindfulness Association (2011, 2013). Mindfulness Based Living Course (MBLC) Course Manual, Unpublished: United Kingdom. 
Nairn, R. et al. 2019. From Mindfulness to Insight. Boulder: Shambhala.

Rose, Simon. 2017. The Lived Experience of Improvisation: In Music, Learning and Life. Bristol: Intellect.

Spolin, Viola. 2001. Theatre Games for the Lone Actor: A Handbook. Evanston Illinois: North-Western University Press.

Spolin, Viola. 1999 [1963]. Improvisation for the Theatre ( ${ }^{\text {rd }}$ Edition). Evanston Illinois: North-Western University Press.

Tint, Barbara \& Froerer, Adam. 2014. Delphi Study Summary. Applied Improvisation Network.

Wunder, Al. Don't educate them out of educating themselves': A conversation between Al Wunder and Anton Krueger' The Journal of Performance and Mindfulness. 2021.

\footnotetext{
'IMAGE: "Nothing Forever," by John Marron, watercolour and ink (2002), in The Art of Is, by Stephen Nachmanovitch (2019).
} 